\title{
Neuroimaging findings of Zika virus infection
}

\author{
Viroj Wiwanitkit ${ }^{1,2}$
}

Received: 11 October 2016 / Accepted: 20 October 2016 / Published online: 1 November 2016

(C) Japan Radiological Society 2016

\section{Dear Editor,}

The article on Zika virus infection is very interesting. Zare Mehrjardi et al. noted that "the main neuroimaging findings in congenital ZIKV infection include microcephaly which is the hallmark of the disease, other malformations of cortical development" [1]. In fact, the neuroimaging in cases of Zika virus infection is very interesting.

It should be noted that the findings might vary in different settings. Based on the findings in Southeast Asia, where Zika virus infection is also endemic, the main finding is no abnormality [2]. The usefulness of neuroimaging investigations seems limited. Asymptomatic infections are very common [3], and negative neurological findings should not be forgotten.

\section{Compliance with ethical standards}

Conflict of interest The author declares that the author has no conflict of interest.

\section{References}

1. Zare Mehrjardi M, Keshavarz E, Poretti A, Hazin AN. Neuroimaging findings of Zika virus infection: a review article. Jpn J Radiol. 2016. doi:10.1007/s11604-016-0588-5.

2. Wiwanitkit V. The current status of Zika virus in Southeast Asia. Epidemiol Health. 2016;16(38):e2016026.

3. Wiwanitkit S, Wiwanitkit V. Afebrile, asymptomatic and nonthrombocytopenic Zika virus infection: Don't miss it! Asian Pac. J Trop Med. 2016;9(5):513.

This comment refers to the article available at doi:10.1007/ s11604-016-0588-5.

Viroj Wiwanitkit

wviroj@yahoo.com

1 Hainan Medical University, Haikou, China

2 Wiwanitkit House, Bangkhae, Bangkok, Thailand 